\title{
Different Medical Features and Strategies of Large Rectal Gastrointestinal Stromal Tumor: A Multi-Central Pooling Analysis
}

This article was published in the following Dove Press journal: Cancer Management and Research

\author{
Chen $\mathrm{Li}\left(\mathbb{D I}^{1}\right.$ \\ $\mathrm{HaO} \mathrm{Wu}^{2}$ \\ $\mathrm{Han} \mathrm{Li}^{3}$ \\ Quan Wang' \\ Yang Li ${ }^{1}$ \\ Zhi-Dong Gao' \\ Xiao-Dong Yang' \\ Ying-Jiang $\mathrm{Ye}^{\prime}$ \\ Ke-Wei Jiang'
}

'Department of Gastroenterological Surgery, Laboratory of Surgical Oncology, Beijing Key Laboratory of Colorectal

Cancer Diagnosis and Treatment Research, Peking University People's Hospital, Beijing, People's Republic of China; ${ }^{2}$ Department of

Gastroenterological Surgery, Shandong Provincial Hospital, Cheeloo College of Medicine, Shandong University, Jinan, Shandong Province, People's Republic of China; ${ }^{3}$ Department of General Surgery, The First Affiliated Hospital of Shandong First Medical University, Jinan, Shandong Province, People's Republic of China
Correspondence: Ke-Wei Jiang Department of Gastroenterological Surgery, Laboratory of Surgical Oncology, Beijing Key Laboratory of Colorectal Cancer Diagnosis and Treatment Research, Peking University People's Hospital, No. II Xizhimen South Street, Xicheng District, Beijing, 100044, People's Republic of China

$\mathrm{Tel}+86$ I35 II07 8I78

Fax +86 (I0) 88326600

Email jiangkewei@pkuph.edu.cn
Purpose: The rectum is a rare site for gastrointestinal stromal tumors (GISTs). Tumors in this critical anatomical site are prone to develop local recurrence, and this occurs at a high level even in low-risk tumors. Previous studies found that high-risk was the most common category in rectal gastrointestinal stromal tumors (RGISTs), and size was the most important factor affecting the long-term prognosis. We aimed to find out the most influential factor on clinical outcomes, and describe demographics, oncological differences, and surgical procedures in patients with poor prognosis.

Patients and Methods: Data on consecutive patients with RGIST, who were diagnosed at Peking University People's Hospital, Shandong Province Hospital, and The First Affiliated Hospital of Shandong First Medical University from 2010 to 2020, were retrospectively evaluated. Further, a literature search was conducted by retrieving data from PubMed, EMBASE, and the Cochrane Library databases from inception up to March 20, 2020.

Results: In all, 50 patients were diagnosed with RGIST at three medical centers, and 86 published records were finally included in the literature review. Combined analysis of the whole individual patient data showed that $5.5 \mathrm{~cm}$ was deemed an appropriate cut-off value for L-RGIST, and that patients usually showed a male predominance $(67.59 \%)$, younger age at onset (56.61 years), higher operative difficulty, and poorer prognosis.

Conclusion: Separation of patients with large RGIST from general patients may contribute to the recognition of the oncological characteristics and clinical management of this rare type of tumor.

Keywords: gastrointestinal stromal tumor, rectum, cut-off value, multi-center, operation

\section{Introduction}

Gastrointestinal stromal tumor (GIST), with an estimated unadjusted incidence of $1-1.5 / 100,000 /$ year, is the most common mesenchymal tumor of the gastrointestinal (GI) tract. ${ }^{1}$ It can occur throughout the GI tract, twice as commonly in the stomach $(60 \%)$ as in the small intestine $(30 \%)$, and relatively rarely in the duodenum $(5 \%)$, rectum $(5 \%)$, and elsewhere $(2 \%){ }^{2}$ GIST, whose biological behavior varies from benign to malignant, usually occurs in elderly people (55-65 years, median 63 years) and seldom affects young people under two decades $(0.4 \%){ }^{3,4}$ Several immunohistochemical (IHC) markers, such as CD117 (95\%), CD34 (70\%), DOG$1(96 \%)$, SMA $(25 \%)$, desmin $(<5 \%)$, and S100 (rare), can be observed in GISTs. ${ }^{5,6}$ Most GISTs show an oncogenic mutation in KIT $(80-85 \%)$ or platelet-derived growth factor receptor alpha (PDGFRA; 5-7\%). ${ }^{7}$ 
The rectum is a rare site for tumors, accounting for $3.5-5 \%$ of all GISTs, $0.6 \%$ of all rectal malignant tumors, and $0.1 \%$ of all tumors that originate in the rectum, with a reported incidence of $0.45 / 1,000,000$ annually. ${ }^{6,8-10}$ Hematochezia, obstruction, pain, rectal fullness, and prostatitis-like symptoms are the main complaints of patients with rectal GIST (RGIST) ${ }^{11-15}$ According to some databases, the mean age of RGIST patients is around 62 years old and the tumors are mainly located in the lower twothirds of the rectum. ${ }^{16,17}$

Previous studies showed that high-risk was the most common category ( $86 \%$ ) in RGIST, sharply contrasting with general GIST (20-50\%). ${ }^{12}$ Huynh et al ${ }^{18}$ concluded from univariate analysis that tumor size $(P=0.004)$ was a predictive factor of local recurrence, and Hawkins et al ${ }^{16}$ also found that tumor size was the most important determinant in prognosis after resection, with tumors larger than $5 \mathrm{~cm}$ being associated with a more than twofold increase in overall mortality. In terms of operation, complete resection of the tumor without rupture is essential for optimum radicality, but up to $38 \%$ of patients with RGIST are at risk of incomplete resection despite extensive procedures, ${ }^{19}$ not to mention large size or adhesion to peripheral structures such as the vagina, prostate, or sacrum. In addition, neoadjuvant imatinib has been shown to improve the rates of complete resection, local disease-free rate, and overall survival rate in these tumors. ${ }^{14,20}$ But until now, no standard therapeutic regimens or surgical procedures have been published. It is notable that GIST at this critical anatomical site is more prone to developing one or multiple local recurrences $(50 \%),{ }^{12}$ in contrast to gastric or small intestinal GIST, and this occurs at a high level even in low-risk tumors $(25 \%){ }^{21}$ Accordingly, metastasis from RGIST tends to involve rare organs such as lungs, bone, and adrenal glands. $^{22,23}$ Although it has several differences compared with gastric and intestinal GIST, rectal GIST has similar gene mutations to GIST in other organs. $^{22}$

In this study, we aimed to find out the most influential factor on clinical outcomes based upon the current patients' data from a literature review, and describe the difference between these RGISTs and common RGISTs in patients from three centers and the literature-based patients. Furthermore, an analysis of different tumor sites and surgical procedures was completed, and conclusions on site-associated operative procedures are also given in this study.

\section{Materials and Methods}

\section{Multi-Central Patients}

Patient Registration

To fully describe the demographic and oncological characteristics, we retrospectively collected patients' data from Peking University People's Hospital (PKUPH), Shandong Province Hospital, and The First Affiliated Hospital of Shandong First Medical University. Patients' information was extracted from the electronic medical records system, and follow-up outcomes were acquired by telephone conversations and outpatient visits.

\section{Inclusion and Exclusion Criteria}

From this, the inclusion criteria for RGIST patients were: 1) tumor diagnosed as GIST which originated from the rectum by pathological outcomes, and 2) patients who underwent operation in these three centers. Accordingly, patients were excluded if: 1) the rectal tumor was not the primary RGIST or 2) patients had more than one tumor in the rectum, regardless of whether the neoplasms were GIST or not.

\section{Literature-Based Patients} Literature Retrieval

We searched the following electronic databases: PubMed, EMBASE, and the Cochrane Library. The search was completed on 20 March 2020. All published studies were searched, without any language restrictions. The search items were as follows: gastrointestinal stromal tumor, rectum, rectal, using Medical Subject Headings terms combined with free text terms. We also performed a supplementary literature search through Google Scholar. All search strategies were determined after numerous pre-searches.

\section{Study Selection and Data Extraction}

Endnote software (version X9.2; Thomson Reuters, Philadelphia, PA, USA) was used to remove duplicates and facilitate the screening process. After two reviewers had independently screened the titles and abstracts, unsuitable studies were excluded, as well as observational studies after reading the full text. Finally, the eligible trials were identified. Disagreements were resolved through discussions. In some conditions, case reports might be used as a part of a patient group in the same author's or other authors' studies, and we excluded these patients' data from the latter and reserved the case reports.

Two reviewers independently extracted the following data: title, year of publication, demographic characteristics, 
operative information, oncological features, pathological results, and follow-up.

\section{Inclusion and Exclusion Criteria}

As shown in Figure 1, we retrieved studies which focused on patients with RGIST from PubMed, EMBASE, and the Cochrane Library, using the keywords listed in the subsection "Literature Retrieval". By screening titles and abstracts, records such as case reports/series, original research, or reviews with detailed patient information were included. Then, full-text articles were assessed for eligibility: those either concerning non-primary RGIST or having incomplete information (such as lacking tumor location) were excluded. In the full-text article assessment, literature-based patients were included if: 1) patients were diagnosed with primary RGIST; and 2) demographics, oncological, and surgical information were detailed. Accordingly, studies were excluded if they met the following criteria: 1) patients had not accepted surgery; 2) there was a lack of vital information on patients and tumors, such as tumor size.

\section{Surgical Procedures}

Referring to surgical procedures, all the selections strictly followed the guidelines, and discussion by a multidisciplinary team and patients' choice played a vital role in patients with a complicated location.

According to the exposure methods and excision range, we classified the surgical procedure into five groups. Group I was tumor exenteration, including polypectomy and endoscopic submucosal dissection. Group II was transanal local excision, including transanal endoscopic microsurgery (TEM) and transanal minimally invasive surgery (TAMIS). Group III was nontransanal local excision, including transabdominal or transsacral pathways. Group IV was transanal rectectomy, including transanal total mesorectal excision (TaTME). Group V was non-transanal rectectomy, including abdominoperineal resection (APR), pelvic exenteration, extralevator abdominoperineal excision (ELAPE), low anterior resection (LAR), and total mesorectal excision (TME).

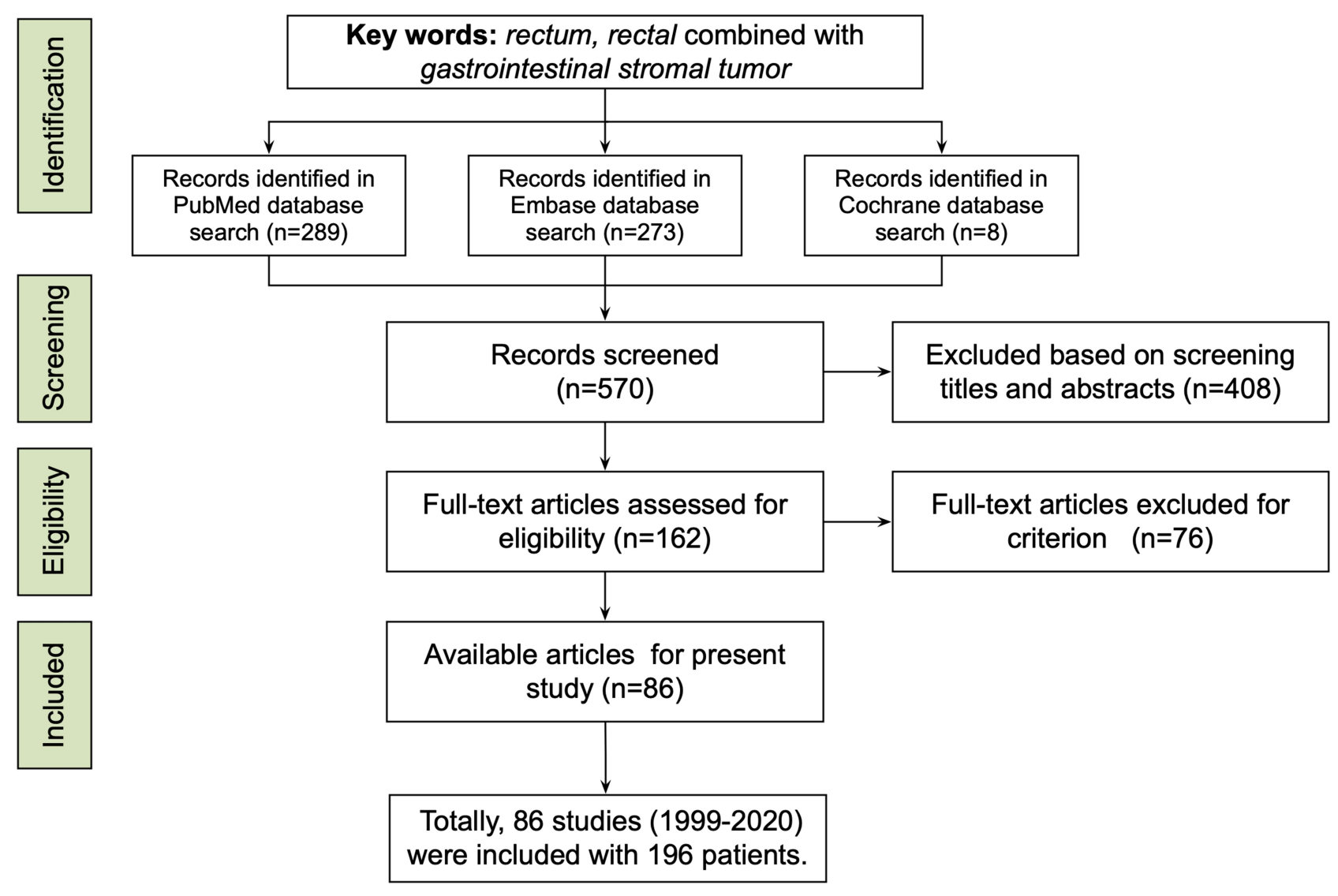

Figure I The study used key words such as rectum, rectal, and gastrointestinal stromal tumor to conduct a literature search in PubMed, Embase, and Cochrane Library, and screened 570 records. According to the inclusion and exclusion criteria, 86 studies including 196 patients were available from 1999 to 2020. 


\section{Statistical Analysis}

Continuous variables were expressed as means and categorical variables were expressed as number (\%). KaplanMeier survival function and statistical analyses were conducted using SPSS software (version 25.0; IBM Corp., Armonk, NY, USA), unless otherwise indicated.

We conducted Cox regression analysis for univariate and multivariate analyses and to obtain an applicable cutoff value of the tumor's maximum diameter for prognosis of RGIST; furthermore, we defined a series of cut-off values every $0.5 \mathrm{~cm}$ from 1 to $10 \mathrm{~cm}$. According to the regression results, the cut-off value was determined with the largest Harrell's $C$ index, largest HR, and $P<0.05$.

\section{Results}

\section{Literature-Based Patients}

From Table 1, after data extraction of 86 studies, 196 patients with RGIST were included. Male patients accounted for $61.2 \%$, and the mean age was 58.45 (SD 12.64) years, ranging from 19 to 88 years.

With regard to tumor features, the mean size of tumors was $5.91(\mathrm{SD} 3.73) \mathrm{cm}$, with a mean distance of 3.42 (SD $2.08) \mathrm{cm}$ from the anal verge. According to modified NIH categories, 18, 28, four, and 113 patients were very low, low, median, and high risk, respectively. Among 196 patients, only 12 patients were recorded as having multiple-organ involvement.

Before surgery, 106 patients had complete records, and $47.17 \%$ of them accepted neoadjuvant imatinib; accordingly, 43.22\% (51/118) patients accepted adjuvant imatinib. With regard to the operative procedure, groups I$\mathrm{V}$ contained 10, 33, 45, one, and 100 patients, respectively; and $15.6 \%$ of patients $(12 / 77)$ had a positive margin identified by the pathological results.

After a mean 43.36-year follow-up duration, $70.00 \%$ of patients (119/170) were alive without any evidence of recurrence and metastasis, 18.82\% (32/170) had relapsed, $14.12 \%(24 / 170)$ had metastasis, and 20 patients had died during follow-up. Among the 24 patients with metastasis, 17 metastatic lesions were found on the liver, followed by pulmonary metastasis.

\section{Multi-Central Patients}

According to Table 1, during the decade January 2010 to January 2020, 50 patients were identified from Peking University People's Hospital, Shandong Province Hospital, and The First Affiliated Hospital of Shandong
First Medical University in northern China. Patients were aged from 27 to 81 years, with a mean age of 52.86 (SD 12.50) months, and males accounted for $60 \%(30 / 50)$ of RGIST patients.

With regard to oncological features, the mean size was 4.82 (SD 3.44) $\mathrm{cm}$, and the mean distance from the anal verge was 3.78 (SD 1.88) $\mathrm{cm}$. In eight patients the tumor had invaded other organs, comprising $16 \%$ of the total patients. Combined with maximum size and mitosis, the number of patients with a recurrence risk from very low to high was eight, 14 , four, and 22 , respectively.

In the perioperative period, 14 patients received neoadjuvant chemotherapy (imatinib, IM), and 22 patients accepted adjuvant therapy (IM). According to the analyses, only one patient underwent enucleation, 35 patients underwent local excision, of whom 31 patients were assigned to group II and four patients to group III. Among the rectectomy group, 14 patients underwent a non-transanal approach and no patients had transanal rectectomy. After the pathological examination, two patients showed positive surgical margins.

According to telephone conversations and outpatient visits, five patients relapsed and two patients had hepatic metastasis after a mean follow-up duration of 45.32 (9-141, SD 32.50) months.

\section{Large RGIST Patients}

Among the three-center and literature-based patients, univariate and multivariate analyses of prognosis were completed, which showed that tumor size (univariate analysis $P=0.004 / 0.005$; multivariate analysis $P=0.015 / 0.014$ ) was the only decisive factor. Based upon the literature-based patients, a cut-off value was calculated (Supplementary Tables S1-S3), and $5.5 \mathrm{~cm}(P=0.014,95 \%$ CI [1.31, 10.47], $\mathrm{C}$-index 0.61 ) seemed to be an appropriate value. Moreover, when the cut-off value was used for the multi-central patients, it also showed an acceptable accuracy $(P=0.008$, 95\% CI [2.27, 238.37], C-index 0.79). Thus, we defined a large RGIST (L-RGIST) as a tumor no smaller than $5.5 \mathrm{~cm}$, which had relatively poor prognosis, and other tumors were defined as non-large RGIST (NL-RGIST).

With regard to L-RGIST patients, 67.59\% (73/108) were male, with a mean age of 56.61 (19-85, SD 12.46) years. Compared with demographic features of patients with NLRGIST, the L-RGIST group showed a trend toward more male $(67.59 \%$ vs $61.16 \%)$ and young (56.61 vs 57.98$)$ patients. The mean size of tumors was 8.48 (SD 3.41) cm, and all 100 recorded tumors had a high recurrence risk. 
Table I Clinical and Oncological Features of Patients with RGIST

\begin{tabular}{|c|c|c|c|c|}
\hline & $\begin{array}{l}\text { Literature-Based Patients } \\
(n=196)\end{array}$ & $\begin{array}{l}\text { Multi-Central Patients } \\
(n=50)\end{array}$ & $\begin{array}{l}\text { L-RGIST Patients } \\
(n=108)\end{array}$ & $\begin{array}{l}\text { NL-RGIST Patients } \\
(n=|2|)\end{array}$ \\
\hline Sex & Valid=I84 & Valid=50 & Valid= 108 & Valid=121 \\
\hline Male & 120 (65.22\%) & $30(60.00 \%)$ & 73 (67.59\%) & 74 (61.16\%) \\
\hline Age (years) & Valid $=184$ & Valid $=50$ & Valid $=108$ & Valid $=121$ \\
\hline Range & $19-88$ & $27-81$ & $19-85$ & $27-88$ \\
\hline Mean (SD) & $58.45(12.64)$ & $52.86(12.50)$ & $56.61(12.46)$ & $57.98(13.05)$ \\
\hline Size $(\mathrm{cm})$ & Valid=178 & Valid $=50$ & Valid $=108$ & Valid= $|2|$ \\
\hline Range & $0.3-35$ & $0.5-18$ & $5.50-35$ & $0.3-5.3$ \\
\hline $0-2$ & $21(11.80 \%)$ & 7 (I4.00\%) & $0(0.00 \%)$ & $36(29.75 \%)$ \\
\hline $2-5$ & 50 (28.09\%) & 22 (44.00\%) & $0(0.00 \%)$ & $83(68.60 \%)$ \\
\hline $5-10$ & 89 (50.00\%) & $16(32.00 \%)$ & 85 (78.70\%) & $2(1.65 \%)$ \\
\hline $10-$ & $18(10.11 \%)$ & $5(10.00 \%)$ & $23(21.30 \%)$ & $0(0.00 \%)$ \\
\hline Mean (SD) & 5.91 (3.73) & $4.82(3.44)$ & $8.48(3.4 I)$ & $3.16(1.42)$ \\
\hline Risk & Valid $=163$ & Valid $=48$ & Valid $=100$ & Valid $=107$ \\
\hline Very low & $18(11.04 \%)$ & $8(16.67 \%)$ & $0(0.00 \%)$ & $26(24.30 \%)$ \\
\hline Low & 28 (17.18\%) & 14 (29.17\%) & $0(0.00 \%)$ & 42 (39.25\%) \\
\hline Intermediate & 4 (2.45\%) & 4 (8.33\%) & $0(0.00 \%)$ & 8 (7.48\%) \\
\hline High & 113 (69.33\%) & 22 (45.83\%) & 100 (I00.00\%) & 31 (28.97\%) \\
\hline Distance $(\mathrm{cm})$ & Valid=135 & Valid $=50$ & Valid $=81$ & Valid $=101$ \\
\hline Range & $0-12$ & $1-10$ & $0-10$ & $0-10$ \\
\hline $0-5$ & 102 (75.56\%) & 35 (70.00\%) & 59 (72.84\%) & 76 (75.25\%) \\
\hline $5-10$ & 30 (22.22\%) & $13(26.00 \%)$ & 19 (23.46\%) & 24 (23.76\%) \\
\hline 10 & 3 (2.22\%) & $2(4.00 \%)$ & $3(3.70 \%)$ & I (0.99\%) \\
\hline Mean (SD) & $3.42(2.08)$ & $3.78(1.88)$ & $3.49(2.21)$ & 3.49 (I.70) \\
\hline \multicolumn{5}{|l|}{ Organ Involvement } \\
\hline Positive & $12(6.12 \%)$ & $8(16.00 \%)$ & $16(14.81 \%)$ & $3(2.48 \%)$ \\
\hline \multicolumn{5}{|l|}{ Adjuvant Therapy } \\
\hline Pre-IM & Valid $=106$ & Valid $=50$ & Valid $=64$ & Valid $=75$ \\
\hline Positive & $50(47.17 \%)$ & $14(28.00 \%)$ & 31 (48.44\%) & $24(32.00 \%)$ \\
\hline Post-IM & Valid=11 18 & Valid $=50$ & Valid $=74$ & Valid $=77$ \\
\hline Positive & $51(43.22 \%)$ & 22 (44.00\%) & 37 (50.00\%) & $26(33.77 \%)$ \\
\hline \multicolumn{5}{|l|}{ Surgical Outcomes } \\
\hline Approach & Valid $=189$ & Valid $=50$ & Valid $=105$ & Valid $=118$ \\
\hline Group I & $10(5.29 \%)$ & I (2.00\%) & $2(1.90 \%)$ & $8(6.78 \%)$ \\
\hline Group II & $33(17.46 \%)$ & $31(62.00 \%)$ & 15 (14.29\%) & 48 (40.68\%) \\
\hline Group III & 45 (23.8I\%) & $4(8.00 \%)$ & $21(20.00 \%)$ & $19(16.10 \%)$ \\
\hline Group IV & I (0.53\%) & $0(0.00 \%)$ & $0(0.00 \%)$ & I (0.85\%) \\
\hline Group V & 100 (52.91\%) & $14(28.00 \%)$ & $67(63.81 \%)$ & $42(35.59 \%)$ \\
\hline Margin & Valid=77 & Valid $=48$ & Valid $=54$ & Valid $=69$ \\
\hline Positive & $12(15.58 \%)$ & $2(4.17 \%)$ & 7 (12.96\%) & 5 (7.25\%) \\
\hline \multicolumn{5}{|l|}{ Follow-Up } \\
\hline Duration (months) & Valid $=165$ & Valid $=37$ & Valid $=89$ & Valid $=99$ \\
\hline Range & $\mathrm{I}-294$ & $9-14 \mid$ & $1-192$ & $\mathrm{I}-294$ \\
\hline Mean (SD) & $43.36(4 I .284)$ & $45.32(32.50)$ & $36.01(31.07)$ & $48.76(44.57)$ \\
\hline
\end{tabular}

(Continued) 
Table I (Continued).

\begin{tabular}{|c|c|c|c|c|}
\hline & $\begin{array}{l}\text { Literature-Based Patients } \\
(n=196)\end{array}$ & $\begin{array}{l}\text { Multi-Central Patients } \\
(n=50)\end{array}$ & $\begin{array}{l}\text { L-RGIST Patients } \\
(n=108)\end{array}$ & $\begin{array}{l}\text { NL-RGIST Patients } \\
(n=|2|)\end{array}$ \\
\hline Outcomes & Valid $=170$ & Valid $=37$ & Valid $=93$ & Valid $=100$ \\
\hline Recurrence & 32 (I8.82\%) & 5 (13.5 I\%) & $20(21.51 \%)$ & 17 (14.91\%) \\
\hline Metastasis & 24 (14.12\%) & 2 (5.4I\%) & $17(18.28 \%)$ & 9 (7.89\%) \\
\hline ANED & 119 (70.00\%) & 29 (78.38\%) & $6 \mathrm{I}(65.59 \%)$ & 81 (81.00\%) \\
\hline AWD & 31 (18.24\%) & 7 (I8.92\%) & 21 (22.58\%) & II (II.00\%) \\
\hline DOD & II (6.47\%) & $0(0.00 \%)$ & $8(8.60 \%)$ & $4(4.00 \%)$ \\
\hline DOC & 9 (5.29\%) & I (2.70\%) & $3(3.23 \%)$ & 4 (4.00\%) \\
\hline
\end{tabular}

Abbreviations: SD, standard deviation; IM, imatinib; ANED, alive with no evidence of disease; AWD, alive with disease; DOD, dead of disease; DOC, dead of other causes.

Tumors were predominantly located a mean of $3.49 \mathrm{~cm}$ from the anal verge, and $16(14.81 \%)$ of them had invaded peripheral organs, which was much more than for NL-RGIST $(2.48 \%)$.

Among the patients receiving adjuvant therapy, 31 of 64 patients (48.44\%) had been given preoperative IM, and 37 of 74 patients $(50 \%)$ post-operative IM. Of the 31 patients who received preoperative IM, three had no detailed information on tumor size before IM, and the mean size of tumors before and after IM was $8.5 \mathrm{~cm}$ and $5.5 \mathrm{~cm}$, respectively.

In regard to surgical outcomes, two L-RGISTs (1.90\%) were resected by enucleation, $15(14.29 \%)$ were resected by transanal local excision, 21 (20.00\%) were resected by nontransanal local excision, and 67 (63.81\%) were resected by non-transanal rectectomy, and seven patients out of 54 records $(12.96 \%)$ had non-R0 resection. Compared with NLRGIST, fewer transanal local excisions (14.29\% vs $40.68 \%$ ) and more group V operations (63.81\% vs $35.59 \%)$ were specified in L-RGIST surgery.

Finally, according to the follow-up outcomes, 61 patients (65.59\%) were healthy, 20 (21.51\%) had relapsed, and 17 (18.28\%) had metastasis (15 were hepatic metastasis). Notably, in NL-RGIST patients (total 114 patients), 17 patients $(14.91 \%)$ had relapsed and nine $(7.89 \%)$ had metastasis (four were hepatic metastasis). Figure 2 shows that the 3-year, 5-year, and 10-year recurrence-free survival rates were $78.7 \%, \quad 53.9 \%$, and $13.8 \%$, respectively. Correspondingly, 3-year, 5-year, and 10-year overall survival rates were $90.1 \%, 87.3 \%$, and $40.9 \%$, as shown in Figure 3.

\section{Discussion}

GIST derived from the rectum, which is in a critical anatomical site, is usually associated with high operative difficulty, high recurrence rates, and poor prognosis. Moreover, primary GIST originating from the vagina or prostate is very rare, but RGIST, especially located on the anterior wall of the rectum, is more likely to clinically mimic vagina/prostate-derived tumors. ${ }^{24,25}$ Several large published studies $^{16,26-28}$ have already described the demographic and oncological features of RGIST and demonstrated that tumor size is associated with clinical outcomes, but studies have rarely defined what L-RGIST is or described L-RGIST.

Based upon the univariate and multivariate analyses of patients from three centers and literature-based patients, we concluded that tumor size was the only impact factor, and $5.5 \mathrm{~cm}$ was the proper cut-off value to distinguish L-RGIST. Compared with L-RGIST, NL-RGIST, which is smaller than $5.5 \mathrm{~cm}$, showed 3-, 5-, and 10-year recurrence-free survival rates of $88.9 \%, 82.2 \%$, and $61.4 \%$, respectively (the 3-, 5-, and 10-year overall survival rates were $93.4 \%, 90.8 \%$, and $85.4 \%$, respectively), and obviously has a better prognosis than L-RGIST.

Considering the demographic features, from previous studies, ${ }^{16,26,27}$ RGIST showed a male predominance, although it was not obvious in some studies. ${ }^{12}$ GIST usually occurs equally in male and female patients, ${ }^{1}$ so we can suppose that RGIST, especially L-RGIST in our study, has a unique pathogenic factor that is different from gastric or small intestinal GIST. Age is considered a prognostic factor for RGIST, ${ }^{16}$ and patients were younger than general GIST (mean age 64-69 years) ${ }^{8,9,29}$ and NL-RGIST patients compared with our results and previous studies. ${ }^{11,16,17,26,27}$

With regard to oncological features, tumors between 2 and $10 \mathrm{~cm}$ comprised the main proportion (more than $75 \%$ ) of RGIST, and tumors between 5 and $10 \mathrm{~cm}$ the main proportion of L-RGIS. Whether in L-RGIST or NLRGIST, tumors were usually located in the lower rectum, and the second most frequent site was the middle rectum, which was consistent with previous studies. ${ }^{17,18}$ 


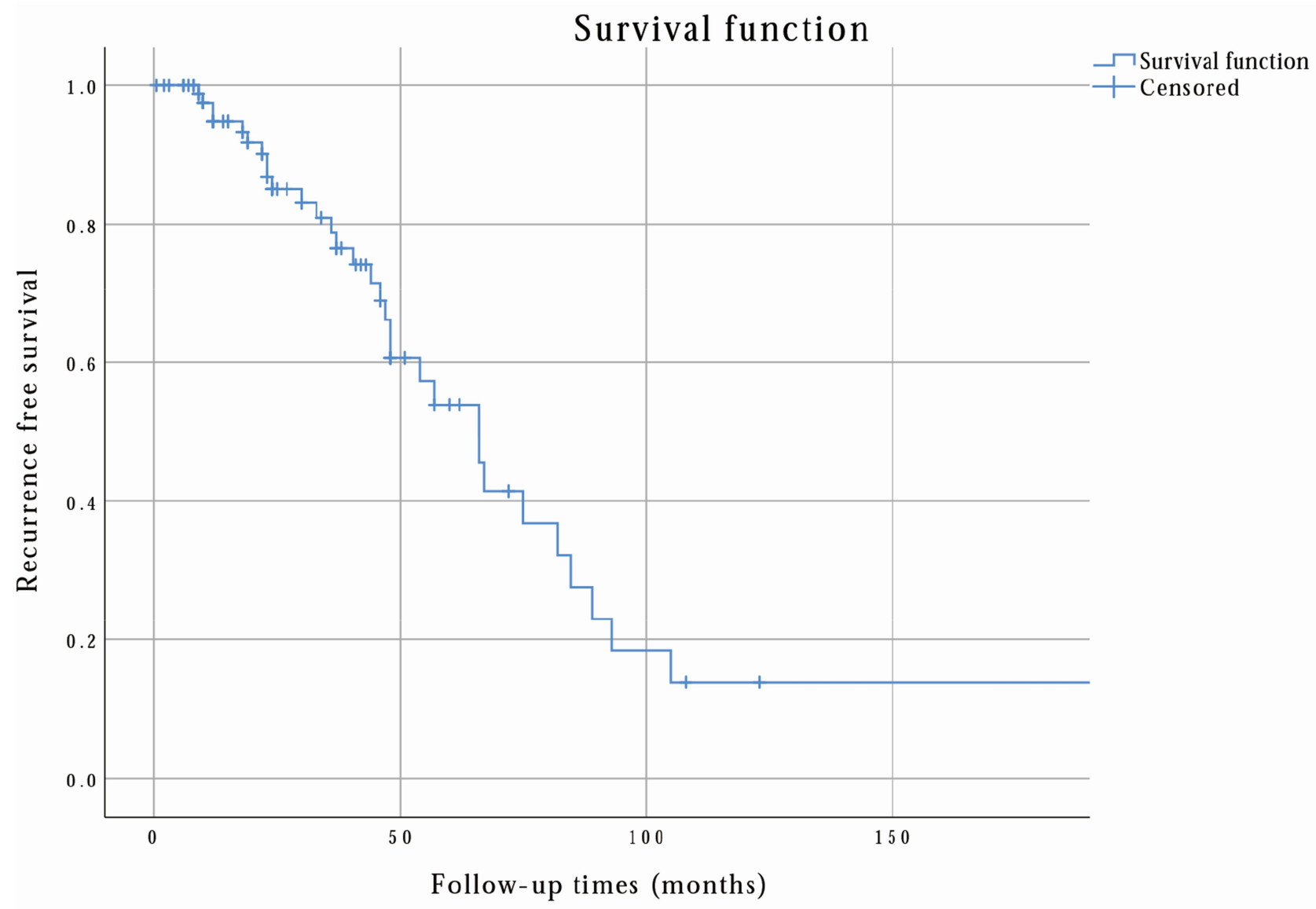

Figure 2 The recurrence-free survival rate of L-RGIST was calculated by the researchers via SPSS. From this analysis, the 3-year, 5-year, and I0-year recurrence-free survival rates were $78.7 \%, 53.9 \%$, and $13.8 \%$, respectively.

According to the literature, up to $38 \%$ of patients with RGIST are at risk of non-radical resection despite extensive procedures. ${ }^{30}$ The primary surgical treatment is important, since incomplete resection may lead to recurrence, and the resection rate of salvage surgery is no more than $60 \% .^{31,32}$ Local excision has the advantages of minimal morbidity and sphincter preservation, while radical excision may offer a better oncological result. ${ }^{33,34}$ For small tumors (less than $5.5 \mathrm{~cm}$, especially intraluminal lesions less than $2 \mathrm{~cm}$ ), transanal local excision/rectectomy may be the first choice when tumors are located in the lower rectum, ${ }^{35}$ but it may inadequate for neoplasms which are difficult to locate exactly, such as extraluminal tumors, adjacent to the prostate, vagina, or sacrum. A study pointed that peritoneal metastasis may not have a hematogenous origin but may be the result of intraoperative tumor cell contamination, ${ }^{20}$ and the poor prognosis of RGIST may associated with the tumor rupture rate being more than four-fold higher than that of GIST in the stomach or small intestine. ${ }^{36}$
When it comes to L-RGIST, the appropriate surgical procedures should be selected depending on the case, aiming for complete gross resection with oncological negative margins, and without bleeding or rupture of the pseudocapsule. Although $72.84 \%$ of tumors were located in the lower rectum, transanal surgery $(17 / 105,16.19 \%)$ was limited because endoscopic inspection may only show the tip of the iceberg, and oncological negative margins are difficult to achieve. According to Table 1, 16.19\% of patients (17/105) in this study underwent local excision. The controversy over rectectomy and local excision arises from whether it is necessary to perform R0 resection at the cost of low quality of life. Although the consensus seems to be that positive margins are associated with poor prognosis, one study ${ }^{37}$ claimed that there was no difference in recurrence-free survival between $\mathrm{R} 0$ and $\mathrm{R} 1$ resection. Changchien et $\mathrm{al}^{38}$ concluded that radical resection had the benefit of decreasing the incidence of tumor recurrence, but not of decreasing metastasis or improving survival. Moreover, aretrospective analysis in 


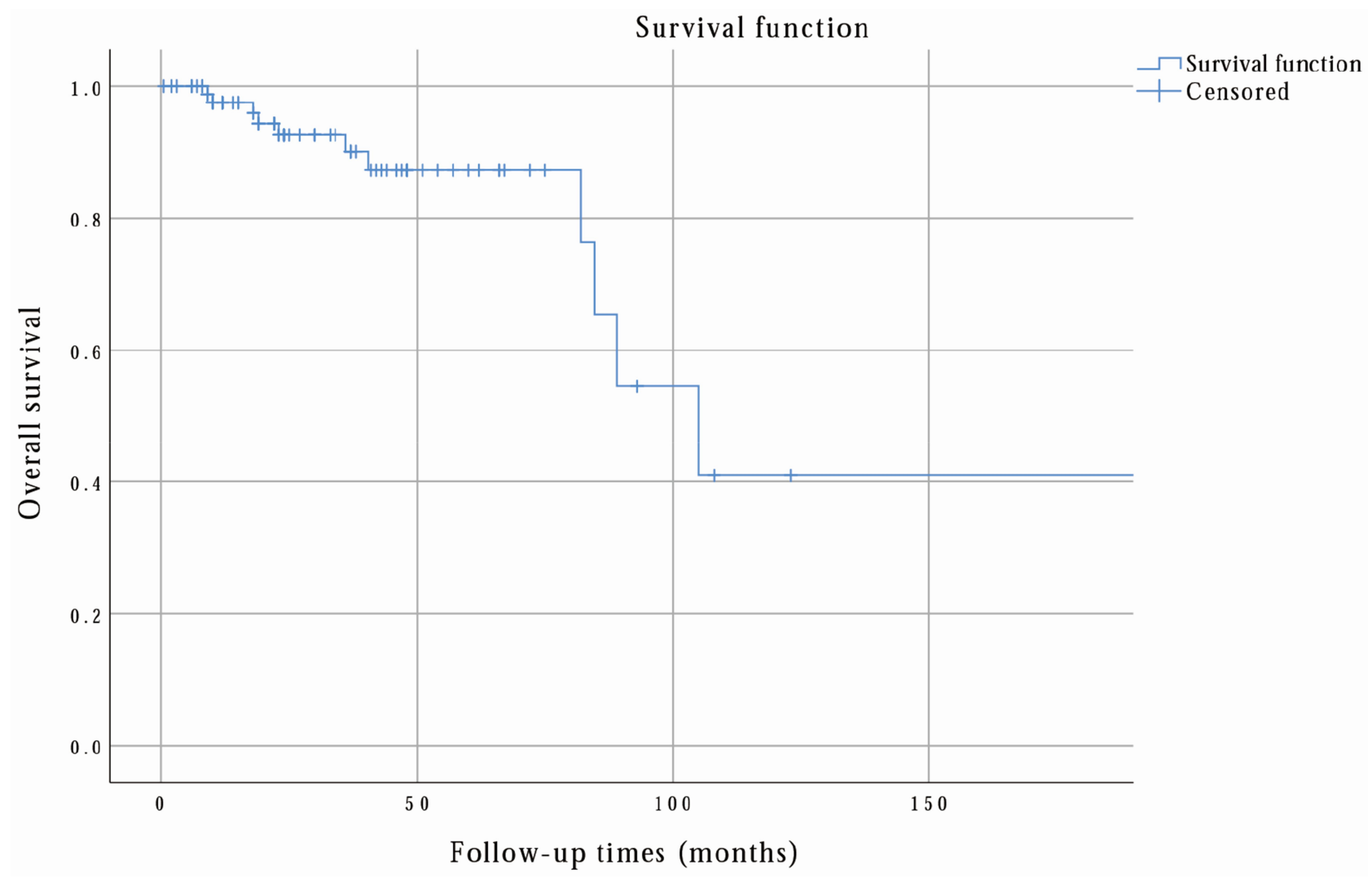

Figure 3 The overall survival rate of L-RGIST was calculated by the researchers via SPSS. From this analysis, the 3-year, 5-year, and I0-year overall survival rates were $90.1 \%$, $87.3 \%$, and $40.9 \%$, respectively.

America ${ }^{16}$ showed that local resection was adequate therapy for tumors smaller than $5 \mathrm{~cm}$, with no difference in overall survival. Owing to limited lymphatic metastasis, mesorectal excision combined with lymphadenectomy, such as TME, is unnecessary. ${ }^{39,40}$ Extended surgery such as APR or multivisceral resection has often been performed in L-RGIST because of adhesion to and invasion of peripheral structures. A transsacral approach has the possibility to obtain excellent exposure and avoid the risk of urogenital dysfunction following TME. ${ }^{33,41}$ Based upon the current Chinese consensus and clinical practice of three medical centers, we reached a conclusion regarding the surgical procedure for RGIST, as shown in Figure 4. Our data may not represent a uniform surgical cohort but rather reflect the real current medical management for primary operable RGIST and L-RGIST after neoadjuvant IM chemotherapy.

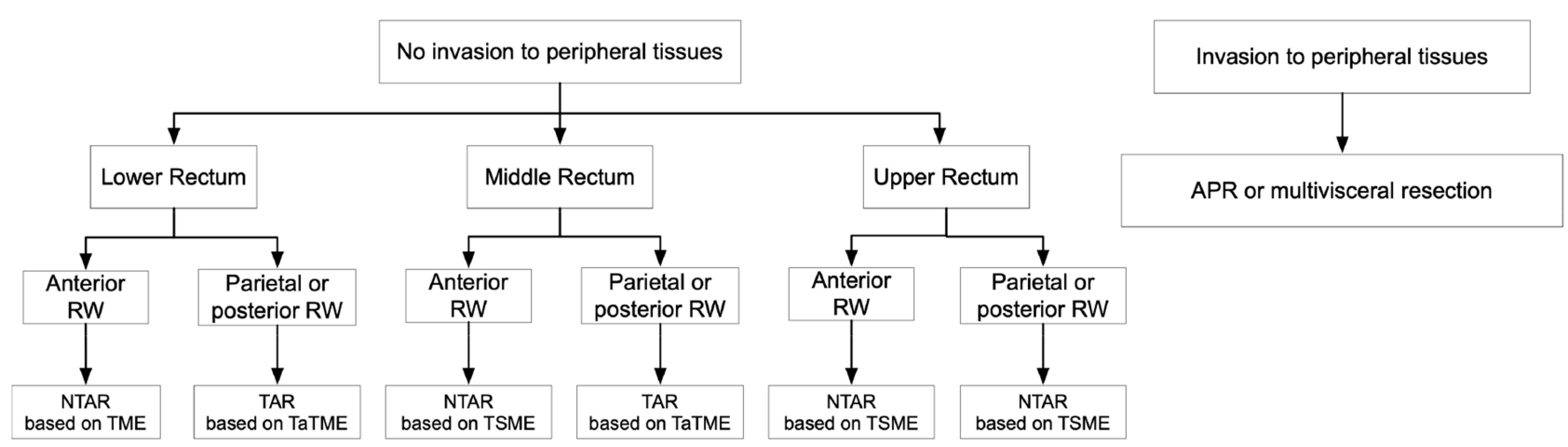

Figure 4 The researchers reached a conclusion on the choice of surgical procedures depending on different tumor sites. In conclusion, transanal resection based upon TaTME and non-transanal resection based upon TME or TSME were the most common and recommended choices based upon Chinese consensus and the clinical practice of three centers. 
Some studies concluded that neoadjuvant therapy can contribute to less extensive surgery, ${ }^{14,21,42}$ while other studies had the converse opinion. ${ }^{39}$ From the latest guidelines $^{43}$ and our clinical practice, RGIST patients whose tumor was too large for en bloc excision, or with no clear boundary between the tumor entity and adjacent organs or vessels, were recommended neoadjuvant chemotherapy with IM before surgery, and the choice of surgical procedures was dependent on the response to IM. In this study, tumor size decreased by a mean of $3 \mathrm{~cm}$ (from $8.5 \mathrm{~cm}$ to $5.5 \mathrm{~cm}$ ) in L-RGIST patients and $2.3 \mathrm{~cm}$ (from $6.6 \mathrm{~cm}$ to $4.3 \mathrm{~cm}$ ) in RGIST patients overall. In L-RGIST patients from three centers, neoadjuvant therapy gave the opportunity for en bloc surgery in these eight patients $(7.4 \mathrm{~cm}$ to $5.9 \mathrm{~cm})$, such as making a clear tumor boundary with peripheral structures and vessels. The surgical procedures of L-RGIST were similar to general RGIST, but we could not obtain similar results in the literature-based L-RGIST patients because detailed information was not available.

With regard to clinical outcomes, comparing L-RGIST and NL-RGIST, both the recurrence rate $(21.51 \%$ vs $14.91 \%)$ and metastatic rate $(18.28 \%$ vs $7.89 \%)$ were higher in the L-RGIST group. Notably, the liver was the most susceptible organ in metastatic RGIST patients, and showed a higher rate in L-RGIST than in NL-RGIST (73.08\% vs $44.44 \%$ ). Moreover, nearly all of the relapsed lesions in RGIST patients included in our study were located in the rectal and presacral region, except for one patient with relapse at the penis.

Furthermore, L-RGIST, compared with NL-RGIST, is more prone to peripheral tissue invasion, non-radical resection, and low recurrence-free survival rates. In the era of IM, genotype analysis and precise treatment greatly assist the surgeon in ensuring that a window of opportunity is not missed by delaying surgery in patients who would not benefit from IM or who would benefit from dose escalation. Finally, it is vital for genetic and molecular biological research to investigate differences in pathogenesis.

\section{Acknowledgments}

We would like to thank the library of Peking University for database access and acquiring the full texts, and HongChen Zheng from Peking University for providing help with statistical analysis. Finally, we show our respect to all patients involved in the study.

\section{Disclosure}

The authors declare that they have no competing interests.

\section{References}

1. Soreide K, Sandvik OM, Soreide JA, Giljaca V, Jureckova A, Bulusu VR. Global epidemiology of gastrointestinal stromal tumours (GIST): A systematic review of population-based cohort studies. Cancer Epidemiol. 2016;40:39-46. doi:10.1016/j. canep.2015.10.031

2. Miettinen M, Lasota J. Gastrointestinal stromal tumors-definition, clinical, histological, immunohistochemical, and molecular genetic features and differential diagnosis. Virchows Arch. 2001;438 (1):1-12. doi:10.1007/s004280000338

3. Ducimetiere F, Lurkin A, Ranchere-Vince D, et al. Incidence of sarcoma histotypes and molecular subtypes in a prospective epidemiological study with central pathology review and molecular testing. PLoS One. 2011;6(8):e20294. doi:10.1371/journal.pone.00 20294

4. Joensuu H, Vehtari A, Riihimaki J, et al. Risk of recurrence of gastrointestinal stromal tumour after surgery: an analysis of pooled population-based cohorts. Lancet Oncol. 2012;13(3):265-274. doi:10.1016/S1470-2045(11)70299-6

5. Wang C, Jin MS, Zou YB, et al. Diagnostic significance of DOG-1 and PKC-theta expression and c-Kit/PDGFRA mutations in gastrointestinal stromal tumours. Scand $J$ Gastroenterol. 2013;48 (9):1055-1065. doi:10.3109/00365521.2013.816770

6. Miettinen M, Lasota J. Gastrointestinal stromal tumors - Review on morphology, molecular pathology, prognosis, and differential diagnosis. Arch Pathol Lab Med. 2006;130(10):1466-1478.

7. Heinrich MC, Corless CL, Demetri GD, et al. Kinase mutations and imatinib response in patients with metastatic gastrointestinal stromal tumor. J Clin Oncol. 2003;21(23):4342-4349. doi:10.1200/JCO.20 03.04.190

8. Nilsson B, Bumming P, Meis-Kindblom JM, et al. Gastrointestinal stromal tumors: the incidence, prevalence, clinical course, and prognostication in the preimatinib mesylate era-a population-based study in western Sweden. Cancer. 2005;103(4):821-829. doi:10.1002/ cncr.20862

9. Tryggvason G, Gislason HG, Magnusson MK, Jonasson JG. Gastrointestinal stromal tumors in Iceland, 1990-2003: the icelandic GIST study, a population-based incidence and pathologic risk stratification study. Int J Cancer. 2005;117(2):289-293. doi:10.1002/ ijc. 21167

10. Tryggvason G, Kristmundsson T, Orvar K, Jonasson JG, Magnusson MK, Gislason HG. Clinical study on gastrointestinal stromal tumors (GIST) in Iceland, 1990-2003. Dig Dis Sci. 2007;52 (9):2249-2253. doi:10.1007/s10620-006-9248-4

11. Hamada M, Ozaki K, Horimi T, et al. Recurrent rectal GIST resected successfully after preoperative chemotherapy with imatinib mesylate. Int J Clin Oncol. 2008;13(4):355-360. doi:10.1007/s10147-0070735-1

12. Agaimy A, Vassos N, Märkl B. Anorectal gastrointestinal stromal tumors: a retrospective multicenter analysis of 15 cases emphasizing their high local recurrence rate and the need for standardized therapeutic approach. Int $J$ Colorectal Dis. 2013;28(8):1057-1064. doi:10.1007/s00384-013-1655-3

13. Shen C, Chen H, Yin R, et al. Clinicopathologic, surgical characteristics and survival outcomes of rectal gastrointestinal stromal tumors. Neoplasma. 2015;62(4):610-617. doi:10.4149/neo_2015_073

14. Wilkinson MJ, Fitzgerald JE, Strauss DC, et al. Surgical treatment of gastrointestinal stromal tumour of the rectum in the era of imatinib. Br J Surg. 2015;102(8):965-971. doi:10.1002/ bjs. 9818 
15. Pai VD, Demenezes JL, Patil PS, Saklani AP. Multimodality therapy of rectal gastrointestinal stromal tumors in the era of imatinib-an Indian series. $J$ Gastrointest Oncol. 2016;7(2):262-268. doi:10.3978/j.issn.2078-6891.2015.088

16. Hawkins AT, Wells KO, Krishnamurty DM, et al. Preoperative chemotherapy and survival for large anorectal gastrointestinal stromal tumors: a national analysis of 333 cases. Ann Surg Oncol. 2017;24 (5):1195-1201. doi:10.1245/s10434-016-5706-1

17. Yasui M, Tsujinaka T, Mori M, et al. Characteristics and prognosis of rectal gastrointestinal stromal tumors: an analysis of registry data. Surg Today. 2017;47(10):1188-1194. doi:10.1007/s00595-017-1524-8

18. Huynh TK, Meeus P, Cassier P, et al. Primary localized rectal/pararectal gastrointestinal stromal tumors: results of surgical and multimodal therapy from the French Sarcoma group. BMC Cancer. 2014;14:156. doi:10.1186/1471-2407-14-156

19. Amato A. Colorectal gastrointestinal stromal tumor. Tech Coloproctol. 2010;14(Suppl 1):S91-5. doi:10.1007/s10151-010-0631-y

20. Jakob J, Mussi C, Ronellenfitsch U, et al. Gastrointestinal stromal tumor of the rectum: results of surgical and multimodality therapy in the era of imatinib. Ann Surg Oncol. 2013;20(2):586-592. doi:10.1245/s10434-012-2647-1

21. Kameyama H, Kanda T, Tajima Y, et al. Management of rectal gastrointestinal stromal tumor. Transl Gastroenterol Hepatol. 2018;3:8. doi:10.21037/tgh.2018.01.08

22. Miettinen M, Furlong M, Sarlomo-Rikala M, Burke A, Sobin LH, Lasota J. Gastrointestinal stromal tumors, intramural leiomyomas, and leiomyosarcomas in the rectum and anus: a clinicopathologic, immunohistochemical, and molecular genetic study of 144 cases. $\mathrm{Am}$ $J$ Surg Pathol. 2001;25(9):1121-1133. doi:10.1097/00000478200109000-00002

23. Barriere J, Thariat J, Vandenbos F, Bondiau PY, Peyrottes I, Peyrade F. Diplopia as the first symptom of an aggressive metastatic rectal stromal tumor. Onkologie. 2009;32(6):345-347. doi:10.1159/000215712

24. Lee CH, Lin YH, Lin HY, Lee CM, Chu JS. Gastrointestinal stromal tumor of the prostate: a case report and literature review. Hum Pathol. 2006;37(10):1361-1365. doi:10.1016/j.humpath.2006.06.028

25. Voelzke BB, Sakamoto K, Hantel A, Paner GP, Campbell SC. Gastrointestinal stromal tumor: involvement in urologic patients and recent therapeutic advances. Urology. 2002;60(2):218-222. doi:10.1016/ S0090-4295(02)01739-9

26. Zhu R, Liu F, Grisotti G, et al. Distinctive features of gastrointestinal stromal tumors arising from the colon and rectum. $J$ Gastrointest Oncol. 2018;9(2):231-240. doi:10.21037/jgo.2017.11.12

27. Yang Z, Guo W, Huang R, Hu M, Wang H, Wang H. Transanal versus nontransanal surgery for the treatment of primary rectal gastrointestinal stromal tumors: a 10-year experience in a high-volume center. Ann Translational Med. 2020;8:201. doi:10.21037/atm.2020.01.55

28. Ijzerman NS, Mohammadi M, Tzanis D, Gelderblom H, Smith M. Quality of treatment and surgical approach for rectal Gastrointestinal Stromal Tumour (GIST) in a large European cohort. European $J$ Surgical Oncol. 2020;46:1124-1130. doi:10.1016/j.ejso.2020.02. 033

Cancer Management and Research

\section{Publish your work in this journal}

Cancer Management and Research is an international, peer-reviewed open access journal focusing on cancer research and the optimal use of preventative and integrated treatment interventions to achieve improved outcomes, enhanced survival and quality of life for the cancer patient.
29. Ma GL, Murphy JD, Martinez ME, Sicklick JK. Epidemiology of gastrointestinal stromal tumors in the era of histology codes: results of a population-based study. Cancer Epidemiol Biomarkers Prev. 2014;24(1):298-302. doi:10.1158/1055-9965.EPI-14-1002

30. Baik SH, Kim NK, Lee CH, et al. Gastrointestinal stromal tumor of the rectum: an analysis of seven cases. Surg Today. 2007;37 (6):455-459. doi:10.1007/s00595-006-3424-1

31. Pierie J-PEN. The effect of surgery and grade on outcome of gastrointestinal stromal tumors. Arch Surg. 2001;136(4):383-389. doi:10.1001/archsurg.136.4.383

32. Roberts PJ, Eisenberg B. Clinical presentation of gastrointestinal stromal tumors and treatment of operable disease. Eur J Cancer. 2002;38((Suppl 5)):S37-S38. doi:10.1016/S0959-8049(02)80601-3

33. Gervaz P, Huber O, Morel P. Surgical management of gastrointestinal stromal tumours. British J Surgery. 2009;96:6. doi:10.1002/bjs.6601

34. Hohenberger P, Oladeji O, Licht T, et al. Neoadjuvant imatinib and organ preservation in locally advanced gastrointestinal stromal tumors (GIST). J Clin Oncol. 2009;27(15_suppl):10550. doi:10.12 00/jco.2009.27.15_suppl.10550

35. Chen $\mathrm{CW}, \mathrm{Wu} \mathrm{CC}$, Hsiao $\mathrm{CW}$, et al. Surgical management and clinical outcome of Gastro-intestinal stromal tumor of the colon and rectum. Article. Z Gastroenterol. 2008;46(8):760-765. doi:10.1055/ s-2008-1027243

36. Farid L. alLocalized gastrointestinal stromal tumor of the rectum: an uncommon primary site with prominent disease and treatment-related morbidities. Mol Clin Oncol. 2013;1(1):190-194. doi:10.3892/ mco.2012.25

37. Mccarter MD, Antonescu CR, Ballman KV, et al. Microscopically positive margins for primary gastrointestinal stromal tumors: analysis of risk factors and tumor recurrence. J Am Coll Surg. 2012;215 (1):53-59. doi:10.1016/j.jamcollsurg.2012.05.008

38. Changchien CR, Wu MC, Tasi WS, et al. Evaluation of prognosis for malignant rectal gastrointestinal stromal tumor by clinical parameters and immunohistochemical staining. Article. Dis Colon Rectum. 2004;47(11):1922-1929. doi:10.1007/s10350-004-0687-8

39. Tielen R, Verhoef C, van Coevorden F, et al. Surgical management of rectal gastrointestinal stromal tumors. J Surg Oncol. 2013;107 (4):320-323. doi:10.1002/jso.23223

40. Akiyoshi T, Ueno M, Fukunaga Y, et al. Laparoscopic local excision and rectoanal anastomosis for rectal gastrointestinal stromal tumor: modified laparoscopic intersphincteric resection technique. Dis Colon Rectum. 2014;57(7):900-904. doi:10.1097/DCR.0000000000000146

41. Matsushima K, Kayo M. Transsacral approach to resect a gastrointestinal stromal tumor in the rectum: report of two cases. Surg Today. 2007;37(8):698-701. doi:10.1007/s00595-006-3466-4

42. Liu H, Yan Z, Liao G, Yin H. Treatment strategy of rectal gastrointestinal stromal tumor (GIST). J Surg Oncol. 2014;109(7):708-713. doi: $10.1002 /$ jso. 23562

43. von Mehren M, Kane JM, Bui MM, et al. NCCN guidelines insights: soft tissue sarcoma, version 1.2021. J Natl Compr Canc Netw. 2020;18(12):1604-1612. doi:10.6004/jncen.2020.0058
The manuscript management system is completely online and includes a very quick and fair peer-review system, which is all easy to use. Visit http://www.dovepress.com/testimonials.php to read real quotes from published authors.

\section{Dovepress}

